\title{
Redesign and Optimization Study of Micro-Hydropower Plant in Manica Mozambique
}

\author{
Miguel Meque Uamusse ${ }^{1,2^{*}}$, Jonas V. Matsinhe², Domingos L. P. Macuvele ${ }^{3}$, Kenneth M. Persson ${ }^{1}$ \\ ${ }^{1}$ Division of Water Resources Engineering, Lund University, Lund, Sweden \\ ${ }^{2}$ Faculty of Engineering, Eduardo Mondlane University, Maputo, Mozambique \\ ${ }^{3}$ Universidade Pedagogica (UP), Lichinga, Moçambique \\ Email: *miguel.uamusse@tvrl.lth.se
}

How to cite this paper: Uamusse, M.M., Matsinhe, J.V., Macuvele, D.L.P. and Persson, K.M. (2017) Redesign and Optimization Study of Micro-Hydropower Plant in Manica Mozambique. Energy and Power Engineering, 9, 100-107.

https://doi.org/10.4236/epe.2017.92008

Received: November 9, 2016

Accepted: February 24, 2017

Published: February 27, 2017

Copyright $\odot 2017$ by authors and Scientific Research Publishing Inc. This work is licensed under the Creative Commons Attribution International License (CC BY 4.0).

http://creativecommons.org/licenses/by/4.0/

\begin{abstract}
The micro-hydropower has the technical capability of providing electricity to rural areas in Manica or other isolated place in Mozambique in currently not yet supplied with EDM (Mozambicam electricity Supply Company). Associated that, today more than 12 million of Mozambicans live below the poverty line including in non-electrified areas and most of these populations are rural people. The stochastic ARMA model and Neural Wavelet was built and fitted from the historical 49 years of hydrology predictions. The flow duration curve was plotted based on flow data with objective to find power potential that was $76.8 \mathrm{Kw}$.
\end{abstract}

\section{Keywords}

Micro Hydropower, Renewable Energy, Manica Mozambique

\section{Introduction}

Today more than half or 12 millions of Mozambicans live below the poverty line including in non-electrified areas. Estimated that, all this rural population has no access to electricity services. Furthermore, the rural communities need electricity to illuminate and power their homes, schools and hospitals. With this serious energy crisis, the vast majority of people in Mozambique are living below the poverty line, and especially in the rural areas where most people cannot afford to pay for electricity [1] [2] [3].

Hydropower will play an important role in future for development in Manica district or in the country, because this technology can provide lowest cost of electricity for people if compare with other technology of energy production. 
Although the government faced with high costs of extending electricity grids to rural areas, the mini and micro hydropower system offers relatively economical option to grid extension. The high cost of transmission lines and the very low load factor in Manica district or other rural areas in Manica province, contribute to the non-viability of the grid extension. This kind of energy technology considered for providing clean electricity generation [2] [3] [4] [5].

Promoting this kind of energy has several benefits, including the fact that it is a clean and renewable energy source with no production of wastes during generation.

Chua village has no access to electricity from National Electricity Company's (EDM); the remoteness of the village makes it difficult to be connected to the national grid. The national grid expansion in this village is not expected the near future according to the EDM. The nearest national grid is located some $20 \mathrm{~km}$ west of the village. Features like mountains, absence of big business potential are among the factors that make the national grid extension not viable.

Hydropower energy is playing important role in rural area not only to give energy solutions in societies, but also in environment point, can be solutions of deforestations and contributions for greenhouse effect by reducing use fossil fuel. Another good advantage of this energy is to meet rural energy demand, reduce the pollution of the environment, respond to climate change, and promote the development of the local business with small factory [6].

\section{Methodology}

In order to establish optimizations study of Micro-hydropower in Manica was necessary knowledge of hydrology data to understand flow information's, topography to determine the layout or head site and geological data to assessing the local potential of landslides, seismic profile and sedimentations of river.

\subsection{Data Collections}

The field visit gives an opportunity to investigate the topography, to analyze flow regime of river geological situations and number of potential costumer. After this observation is possible to identify locations of power house and best routing of the water ways and other component of power plant. Final to address the above research was necessary to obtain historical information's like data of rainfall, flow data.

\subsection{Hydrological Modeling}

To estimate the flow, analysis was made by utilizing the available historical flow data records from a nearby gauging station on the Chua River. The time series of flow data recorded for 39 years dated from 1954 to 2004 were used Wavelet neural network model (WNN) and ARMA, the time series of the collected data sample for a period of 48 years was plotted to reveal the trend of flow data.

\subsubsection{Correlations Analysis of Sample Data}

This analysis the objective is to determine the correlations of the data with its 
own past and future values from time series, the sample autocorrelation established based on the auto covariance relationship [9] [10] [11].

$$
\begin{gathered}
\rho_{k}=\frac{\operatorname{Cov}\left(X_{t}, X_{t+1}\right)}{\sigma_{X_{t}} \sigma_{t+k}}=\frac{C_{k}}{C_{o}} \\
C_{k}=\frac{1}{N} \sum_{i=1}^{n-k}\left(X_{t}-\bar{X}\right)\left(X_{t+1}-\bar{X}\right) \\
C_{o}=S_{x}{ }^{2} \frac{1}{N-1} \sum_{t=1}^{N}\left(X_{t}-\bar{X}\right)^{2}
\end{gathered}
$$

where: $C_{k}$ Sample of estimate of covariance, $C_{o}$ Variance of the series and $\sigma_{X_{t+k}}$ is stand pf deviations.

\subsubsection{ARMA Model Formulations}

To fit ARMA model in this time series, three main procedures are used the identification of the model structure, parameter estimation and calibration and model testing or validation. In this ARMA model was consider two categories, the first category is autoregressive AR (p) models and the second category is autoregressive integrated moving average ARIMA ( $\mathrm{p} \mathrm{d}$ ) models, which is are built as combination of autoregressive AR (p) part and the moving average MA(q) part. For a differenced series. The autoregressive (AR (P)) models, also written as ARIMA ( $p$ d q) models are governed by the general Equation (7):

The Differenced series $y_{t}$ is given by bellow equations and consider $X_{t}$ is observed series

$$
\begin{aligned}
& Y_{t}=X_{t}-X_{t+1}=X_{t}-B X_{t} \\
& Y_{t}=X_{t}-X_{t-2}=X_{t}\left(1-B^{2}\right) \\
& Y_{t}=X_{t}-X_{t-3}=X_{t}\left(1-B^{3}\right)
\end{aligned}
$$

The $\operatorname{Ar}(1)$ model or $\operatorname{ARMA}(110)$ is given by Equations 5

$$
Y_{t}=\varphi_{1} Y_{t-1}+\varepsilon_{t}=\varphi_{1} B Y_{t}+\varepsilon_{t}
$$

Substituting Equations 4 into $B X_{t}=X_{t-1}$ we find:

$$
X_{t}\left[1-B-\varphi_{1}\left(B-B^{2}\right)\right]=\varepsilon_{t}
$$

The general form of ARIMA model is given by Equation (7) below,

$$
X\left(1-B-\sum_{i=1}^{p} \varphi_{i}\left(B^{i}-B^{i+1}\right)\right)=\left(1+\sum_{i=1}^{q} \theta_{i} B^{i}\right) e_{t}
$$

where:

$\varphi_{i}$ is series one step behind, $\theta_{i}$ is MA parameter $e_{t}$ is residual series.

\subsubsection{Wavelet Analysis Artificial Neural Network}

Artificial neural network are computational and mathematical model with a wide ranges of applications have great ability in forecasting modeling for nonlinear hydrological time series.

The ANN Procedure through the combination of neural networks to prediction components of frequency up to 5 layers, subsequently combining the simulated network values to reconstruction of the original signal by wavelet technique reconstruction, This Model is basically works with inverse decomposition 
process.

\subsubsection{The Model Performance}

The performance of different forecasting models was accessed in terms of goodness to fit once each of the model structures is calibrated using the training, validation data set and testing data. Degree of correlation was measure $\left(R^{2}\right)$ in Equation (6). The Equation (4) is coefficient of correlation (CE) was used to compare the goodness to fit between the measured flow and the simulated flow. The Mean-squared error (MSE) in Equation (5) used to evaluate the variance of error. To calculate the root-mean-square error (RMSE), mean absolute error(MAE) and mean absolute relative error (MARE) will use remaining Equations in the same literature [7]-[13].

$$
\begin{gathered}
C E=\frac{\sum_{1}^{n}\left(Q_{o b s}-\overline{Q_{o b s}}\right)\left(Q_{\text {pre }}-\overline{Q_{p r e d}}\right)}{\sqrt{\sum_{1}^{n}\left(Q_{o b s}-\overline{Q_{o b s}}\right)^{2}} \sqrt{\sum_{1}^{n}\left(Q_{p r e d}-\overline{Q_{p r e d}}\right)^{2}}} \\
M S E=\sqrt{\frac{\sum\left(Q_{o b s}-Q_{p r e}\right)^{2}}{n}} \\
R^{2}=1-\frac{\sum_{i=1}^{N}\left(Q_{o b s}-Q_{\text {Pre }}\right)^{2}}{\sum_{1=1}^{N}\left(Q_{o b s}-\overline{Q_{o b s}}\right)^{2}} \\
M A E=\frac{\sum_{1}^{n}\left|\left(Q_{o b s}-Q_{p r e d}\right)\right|}{n} \\
M A R E=\frac{1}{n} \sum_{1}^{n} \frac{\left|Q_{o b s}-\overline{Q_{o b s}}\right|}{Q_{o b s}} \\
R S E=\sqrt{\frac{\sum_{1}^{n}\left(Q_{o b s}-Q \operatorname{Pr} e d\right)^{2}}{n}}
\end{gathered}
$$

where: Where $Q_{o b s}$ is corresponds the steam flow observed value, $Q_{p r e}$ is corresponds the predicted flow rate value, and $\bar{Q}$ is the average value of flow rate. MSE is mean square error and CE is coefficient of efficiency and $n$ is number of data point used and $\mathrm{n}$ is number of observed data or sample of size.

\subsection{Determining Flow Duration Curve}

Reestablishing the flow duration curve at Chua Micro-hydro plant, the historical river flow data and the site historical rainfall data was used to establish a cumulative discharge-rainfall curve, so as to examine significant change in stream flow attributes such as magnitude, timing, frequency, duration and rate of change of flow.

\subsection{The Power Potential Available}

The total power productions from Chua micro-hydropower plant is a product of the effective head, the flow rate, and the efficiency of the turbine Equation (10). 


$$
P=\eta \rho g Q H n
$$

where; Net head $(H n)=$ Gross head $(H)$ - Head loss $(h), g$-Gravitational constant is $9.81 \mathrm{~m} / \mathrm{s}^{2}, Q-$ Discharge in $\mathrm{m}^{3} / \mathrm{s}, \eta$-The efficiency of turbine assuming is $0.8, \rho$-Density of the water is $1000 \mathrm{~kg} / \mathrm{m}^{3}$.

\section{Result and Discussion}

\subsection{The Power Potential Available}

Based on the layout of site in Chua the head of this plant was $48 \mathrm{~m}$, the efficiency of the turbine assuming $80 \%$, and design flow according FDC of water is 0.20 $\mathrm{m}^{3} / \mathrm{s}$ during normal season and during the flood season can be $0.5 \mathrm{~m}^{3} / \mathrm{s}$. According to the Equation (10), the available potential computed was $76,800 \mathrm{~kW}$ and the turbine selected according the head and flow was Pelton turbine, which is working in higher head even in low flow conditions.

\subsection{Flow Duration Curve}

After having flow discharge data, FDC plotted. This curve is the first basic analysis for designing a hydropower scheme. FDC shows the percent of time that flow is equal to or more than various rates during the period of study. The FDC shows the percentage probability of the flow magnitude, and

$\mathrm{Q}$ is being the flow equaled or exceeded which in the Figure 1 give $0.3 \mathrm{~m}^{3} / \mathrm{s}$ and is equivalent of $30 \%$ exceedance value in Figure 1.

\subsection{Hydrological Model Analysis}

Any optimizations stud of hydropower plant requires exactly understanding flow characteristics and Hydrology regim study. In this case hydrology flow data of Chua river in Manica. However, realiability of experimental hydrology was done by comparing the performance of ARIMA model, ANN and wavelet hybrid models of 588 month and 49 years. Due to the temporal serie of hydrological

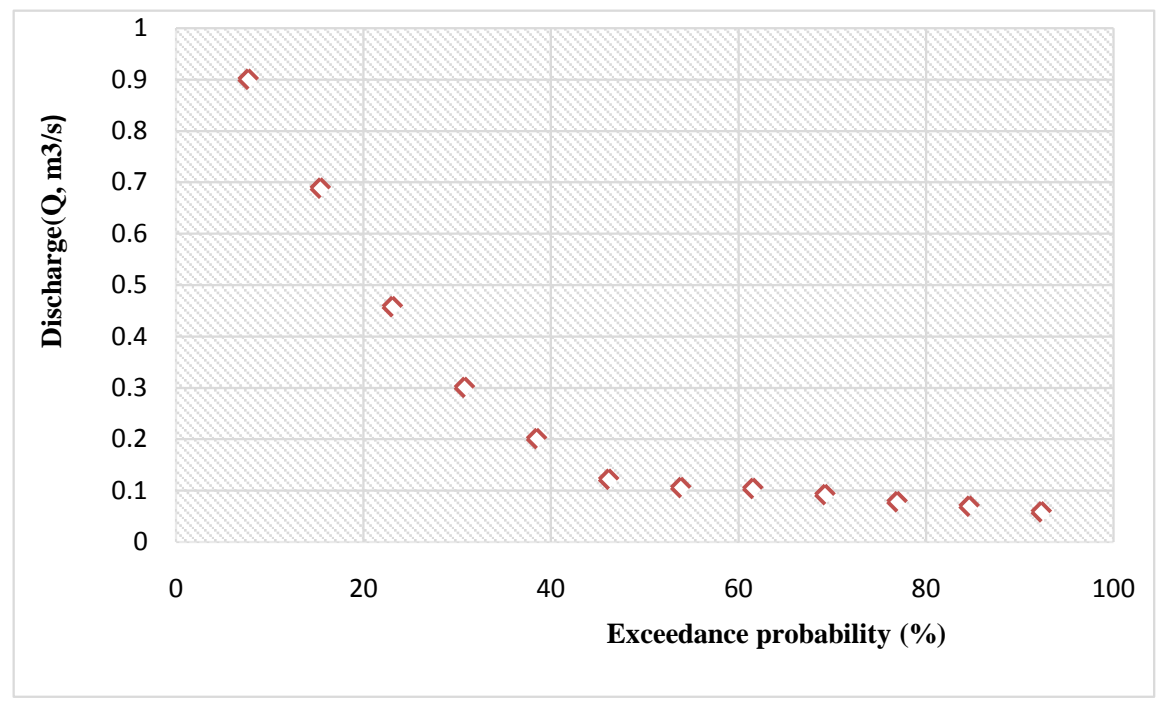

Figuere 1. Flow durations curve in Chua micro hydropower plant. 
process its recommended to use 45 years for first part for training equivalent of 80 percent than, the rest 4 years for verification or test equivalent 20 percent of time series.

The mean square error (MSE), the Root-Mean-Squere (RMSE), Degree of correlation $\left(\mathrm{R}^{2}\right)$ and Nash-Sutcliffe of efficiency (NSE) and coefficient of correlation $(\mathrm{R})$ was selected for prediction in the Table 1.

From ARIMA model the best value is ARIMA 310 model has RMSE, $\mathrm{R}^{2}$ which is 10.18 and 0.92 for training and 22.40 and 0.89 for testing or validations therefore it was selected for both forecasting and long term synthetic data generation.

\subsection{Economy and Environment Analysis of Hydropower}

After this study we find evidence that hydropower is not only renewable energy, but is cheap form of electricity. Compare with fossil power plant like diesel systems there great difference between economic issues. For example the cost of productions currently can be $0.2 \mathrm{USD} / \mathrm{kWh}$ because the influence of higher price of fossil fuel, the methane gas is approximately $0.15 \mathrm{USD} / \mathrm{kWh}$ and cost of Mini and micro hydropower in Manica is expect to be $0.1 \mathrm{USD} / \mathrm{kWh}$ (100 USD = $5000 \mathrm{Mt})$.

Table 1. Hydrological model results.

\begin{tabular}{ccccccc}
\hline & \multicolumn{2}{c}{ Decomposition } & \multicolumn{2}{c}{ Training } & \multicolumn{2}{c}{ Testing } \\
\hline \multirow{2}{*}{$\mathrm{R}^{2}$} & WANN & WANFIS & WANN & WANFIS & WANN & WANFIS \\
RMSE & Sym 3,3 & Db 3,4 & 0.8282 & 0.9061 & 0.6894 & 0.8706 \\
NSE & Sym 3,2 & Db 3,4 & 190.1096 & 139.57 & 179,60 & 123.68 \\
$\mathrm{R}^{2}$ & Coif 1,3 & Db 3,4 5,3 & 0.6150 & 0.729 & 0.5382 & 0.5454 \\
RMSE & Coif 1,3 & Db 5,3 & 199.42 & 178.83 & 172.57 & 164.212 \\
NSE & Coif 1,3 & Db 5,3 & 0.8047 & 0.79 & 0.7813 & -0.421 \\
\hline
\end{tabular}

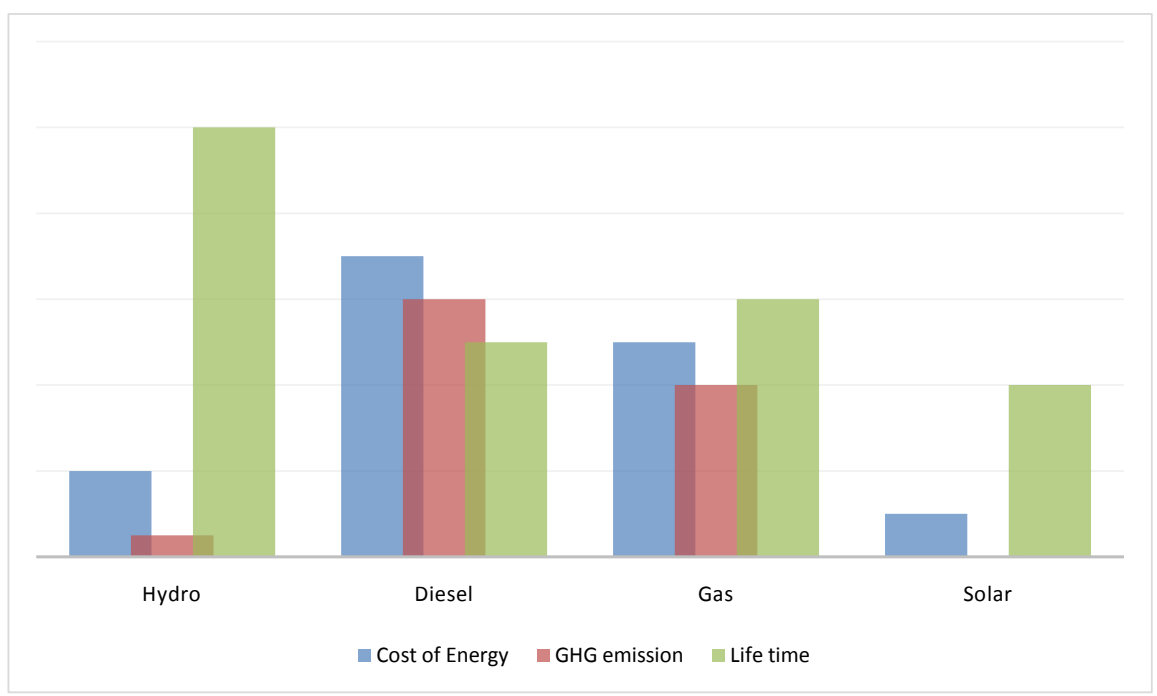

Figure 2. Economy a, environment and Life time Analysis of hydropower. 
After the economic study, we analyzed the environmental component and operating time and Figure 2 show that is evident that Hydropower has long life span and no emissions of Greenhouse gas but diesel and gas plant has many GHG emissions.

\section{Conclusions}

After several studies to reevaluate or optimizing the Micro Hydropower plant at chua Manica chua central, some important analyses have done for positive contribution to increase the energy. The previous capacity was $3420 \mathrm{~kW}$ and new study was $7680 \mathrm{~kW}$ representing double.

In this figure investigation, the flow duration curve is at $30 \%$. The flow available is $0.30 \mathrm{~m}^{3} / \mathrm{s}$ observed in 108 days per year. The important issue is that this value is not for all years. Some period like rains and dry season is changing. The way is an estimated design flow according to Figure 1 represents FDC.

Environmental economic and life time show that hydropower or renewable energy is cheap. Social impact assessment shows that the implementation of the proposed mini-hydropower plant will not cause any significant physical impact in the environmental and social activities.

\section{References}

[1] IRENA (2012) Mozambique RRA Preliminary Findings. http://sdg.iisd.org/news/irena-publishes-renewables-readiness-assessment-of-moza mbique/?rdr=energy-l.iisd.org

[2] Mozambique Advisory Committee (2003) Agenda 2025 Visiona and Strategy of a Nation. Maputo.

[3] MoE (Ministry of Energy) (2008) Energy Management Strategy for the Energy Sector (2008-12). Maputo.

[4] EmíliaInêsCome (2015) Renewable Energy for Rural Electrification and Development in Mozambique. Master of Science Thesis EGI-2015-032MSC.

[5] Ahlborg, H. (2012) Electricity for Better Lives in Rural Tanzania and Mozambique. Chalmers University of Technology, Gothenburg.

[6] Hammar, L., Ehnberg, J., Mavume, A., Boaventura, Cuamba, C. and Molander, S. (2012) Renewable Ocean Energy in the Western Indian Ocean. Renewable and Sustainable Energy Reviews, 16, 4938-4950. https://doi.org/10.1016/j.rser.2012.04.026

[7] Cuamba, B.C., Chenene, M., Mahumane, G., Quissico, D., Lovseth, J. and O'Keefe, P. (2006) Solar Energy Resources Assessment in Mozambique. Journal of Energy for Southern Africa, 17, 76-85.

[8] Renewable Energy under the Ministry of Energy (DNER) (2008) Support for Wind Power Development in Mozambique.

https://energypedia.info/images/c/cb/EN_Support_for_Wind_Power_Development in_Mozambique_report_DNER.pdf

[9] AHEC (2011) Guidelines for Hydraulic Design of Small Hydropower Plants. Ministry of New and Renewable Energy Govt. of India.

[10] Uamusse, M.M., Ndalila, P., Tsamba, A.J., de Oliveira Carvalho, F. and Person, K. (2015) Monthly Stream Flow Predition in Pungwe River for Small Hydropower Plant Using Wavelet Method. International Journal of Energy and Power Engineer- 
ing, 4, 280-286.

[11] Uamussea, M.M. and DinisJuízob, K.M. (2015) Persona Hydro Power Potential in Mozambique "CHUA-MANICA" International Conference on Alternative Energy in Developing Countries and Emerging Economies. Energy Procedia, 79, 719-726.

[12] Wang, W., Gelder, V.P. and Vrijling, K.J. (2005) Improving Daily Stream Flow Forecasts by Combining ARMA and ANN Models. International Conference on Innovation Advances and Implementation of Flood Forecasting Technology, Tromsø.

[13] Wang, W., Pieter, H.A., Gelder, V. and Vrijling, K.J. (2005) Constructing Prediction Intervals for Monthly Stream Flow Forecasts. ISSH-Stochastic Hydraulics, Nijmegen Netherlands.

Submit or recommend next manuscript to SCIRP and we will provide best service for you:

Accepting pre-submission inquiries through Email, Facebook, LinkedIn, Twitter, etc. A wide selection of journals (inclusive of 9 subjects, more than 200 journals)

Providing 24-hour high-quality service

User-friendly online submission system

Fair and swift peer-review system

Efficient typesetting and proofreading procedure

Display of the result of downloads and visits, as well as the number of cited articles Maximum dissemination of your research work

Submit your manuscript at: http://papersubmission.scirp.org/

Or contact epe@scirp.org 